\title{
O CREAS PAEFI NA PERSPECTIVA DE MULHERES VÍTIMAS DE VIOLÊNCIA E PROFISSIONAIS: UMA ANÁLISE A PARTIR DA TEORIA BIOECOLÓGICA DO DESENVOLVIMENTO HUMANO
}

THE CREAS PAEFI IN THE PERSPECTIVE OF VIOLENCE VICTIM WOMEN AND PROFESSIONALS: AN ANALYSIS ACCORDING TO THE BIOECOLOGICAL THEORY OF HUMAN DEVELOPMENT

EL CREAS PAEFI EN LA PERSPECTIVA DE LAS MUJERES VÍCTIMAS DE LA VIOLENCIA Y LOS PROFESIONALES: UN ANÁLISIS DESDE LA TEORÍA BIOECOLÓGICA DE DESARROLLO HUMANO

Nailane Fabris Rosa* Célia Regina Rangel Nascimento ${ }^{* *}$

\begin{abstract}
RESUMO
Estudo qualitativo cujo objetivo foi investigar se o Centro de Referência Especializado da Assistência Social-Proteção e Atendimento Especializado a Famílias e Indivíduos (CREAS PAEFI) de um município do estado do Espírito Santo, compunha a rede de apoio social e afetiva de mulheres vítimas de violência por seus companheiros. Foram entrevistadas 10 mulheres vítimas de violência, usuárias do serviço, e 6 profissionais atuantes na equipe. Os dados foram analisados por meio da análise de conteúdo e discutidos com base na teoria bioecológica do desenvolvimento humano. O serviço foi avaliado positivamente, e as interações entre os profissionais e as mulheres vítimas de violência favoreceram processos proximais que promoveram mudanças positivas nas características pessoais das usuárias, reforçando relações que elas tinham com suas famílias e outros contextos. Concluiu-se que o serviço integrou a rede de apoio socioafetiva dessas mulheres, atuando como um microssistema significativo que favoreceu o desenvolvimento delas diante da situação de violência.
\end{abstract}

Palavras chaves: Violência contra mulher. CREAS. Rede de apoio. Teoria bioecológica.

\section{ABSTRACT}

This qualitative study aims to investigate whether the Specialized Reference Center for Social Assistance and Protection and Specialized Care to

Texto recebido em 26 de maio de 2015 e aprovado para publicação em $1^{\circ}$ de novembro de 2016.

Mestra em Psicologia pelo Programa de Pós-Graduação em Psicologia da Universidade Federal do Espírito Santo (UFES). E-mail: nailanefr@gmail.com.

* Doutora em Psicologia pelo Programa de Pós-Graduação em Psicologia da UFES e docente no Departamento de Psicologia Social e do Desenvolvimento, na mesma universidade.E-mail: celiarrn@gmail.com. 
Families and Individuals (CREAS PAEFI) of a city in the state of Espírito Santo, composed the network of social and emotional support to women victims of violence from their partners. We interviewed 10 women who were victims of violence, and users of the mentioned service, as well as 6 professionals working in the team. The data were studied according to the content analysis research method and discussed in accordance with the Bioecological Theory of Human Development. The service was ranked positively and the interactions between professionals and violence-victim women favored proximal processes that yielded positive changes in the personal characteristics of the service users, strengthening relationships they had with their families and other contexts. Conclusions unveiled that the service turned out to be part of the socio-emotional support network for these women, acting as a significant microsystem that favored their development facing the condition of violence.

Keywords: Violence against women. CREAS. Network support. Bioecological theory.

\section{RESUMEN}

Estudio cualitativo que tuvo como objetivo investigar si el Centro de Referencia Especializada para la Asistencia Social y Protección de Atención Especializada a familias e individuos (CREAS PAEFI) de una ciudad del estado de Espírito Santo, integraba la red de apoyo social y emocional a las mujeres víctimas de violencia por parte de sus compañeros. Entrevistamos a 10 mujeres víctimas de la violencia, usuarias del servicio, así como 6 profesionales que trabajan en el equipo. Los datos fueron analizados mediante el análisis de contenido y discutidos con base en la teoría bioecológica del desarrollo humano. El servicio fue evaluado positivamente y las interacciones entre los profesionales y las mujeres víctimas de la violencia favoreció procesos de aproximación que promovieron cambios positivos en las características personales de las usuarias, el fortalecimiento de las relaciones que tenían con sus familias y otros contextos. Se concluyó que el servicio era parte de la red de apoyo social y emocional de estas mujeres, que actúa como un microsistema significativo que favoreció su desarrollo ante la situación de violencia.

Palabras clave: Violencia contra la mujer. CREAS. Red de apoyo. Teoría bioecológica.

\section{INTRODUÇÃO}

ntre os diversos tipos de violência presentes no espaço social, encontra-se a violência contra a mulher. A Lei ${ }^{\circ} 11.340$, de 7 de agosto de 2006, conhecida como Lei Maria da Penha, define a violência contra a mulher 
como: "Qualquer ação ou omissão baseada no gênero que lhe cause morte, lesão, sofrimento físico, sexual ou psicológico e dano moral ou patrimonial que ocorra no âmbito da unidade doméstica, na família ou em qualquer relação íntima de afeto" (Lei no 11.340, 2006, art. 5).

O Brasil está entre os países com altos índices de violência contra a mulher. Em relação a casos que resultam em homicídio, estudo realizado com 80 países do mundo com base em dados retirados do sistema de estatística da Organização Mundial da Saúde, entre 2006 e 2011, mostrou que o Brasil ocupa a $7^{\text {a }}$ colocação entre os países com elevados níveis de homicídios femininos, tendo uma taxa de 4,4 homicídios em 100 mil mulheres (Waiselfisz, 2012). Contudo, mesmo com esses números elevados, considera-se que muitos casos não são contabilizados, pois situações de violência são ainda toleradas e silenciadas, impedindo que dados qualitativos e quantitativos demonstrem a magnitude do problema (Saffioti, 1997; Santos \& Moré, 2011).

Além das consequências físicas e emocionais da violência, que podem durar meses e até anos (Albuquerque Netto, Moura, Queiroz, Tyrrell \& Bravo, 2014; Villela \& Lago, 2007), verifica-se que algumas estratégias para lidar com a violência sofrida, como o uso de bebidas alcoólicas e de drogas ilícitas (Barros et al., 2016; Peralta \& Fleming, 2003), a perda de dias de trabalho ou do emprego (Rodgers, 1994) podem tornar a mulher ainda mais vulnerável. Além disso, a violência contra a mulher também afeta a família e os filhos, podendo resultar em dificuldades emocionais e de comportamento (Durand, Schraiber, FrançaJunior \& Barros, 2011; Rodrigues, Rodrigues, Lira, Couto \& Diniz, 2016), o que ressalta a necessidade de uma rede de apoio para o indivíduo e a família que vive essa condição.

Estudos mostram que a busca de apoio na família é a primeira estratégia de proteção utilizada pela mulher que sofre violência (Rodrigues et al., 2016; Snow \& Swan, 2006; Vieira, Becker, Souza, Tocantins \& Pina-Roche, 2015). Porém é comum o isolamento social nesses casos e, sem uma rede de apoio social, a percepção que a mulher tem sobre a sua capacidade de mudar de vida é prejudicada (Grossi, Tavares \& Oliveira, 2008; Dutra, Prates, Nakamura \& Villela, 2013).

A rede de apoio social é definida como um conjunto de sistemas e pessoas significativas que compõem os vínculos de relacionamentos que são recebidos e percebidos pelo indivíduo (Brito \& Koller, 1999). Está associada à saúde e ao bem-estar do indivíduo, já que é um fator importante para o processo de adaptação às situações de estresse e peça fundamental no desenvolvimento da pessoa (Juliano \&Yunes, 2014; Samuelson, Thernlund \& Ringstrom, 1996; 
Sluzki, 1997). Os recursos oferecidos pela rede de apoio para o indivíduo em situação de risco podem ser de natureza emocional, material e afetivo (Sherbourne \& Stewart, 1991). Essa rede pode passar por diversas transformações ao longo da vida da pessoa, variando de acordo com o momento do desenvolvimento, as necessidades e também as interações que esta é capaz de desenvolver (Garmezy \& Masten, 1994; Samuelson et al., 1996).

A mulher precisa, para o enfrentamento da violência, de uma rede de apoio composta de relações estáveis, de serviços qualificados e que funcionem em diferentes horários, além de profissionais preparados (Garcia, Duarte, Freitas \& Silva, 2016; Labronici, 2012). No entanto, estudos têm mostrado que a rede de atendimento à mulher vítima de violência é, muitas vezes, identificada como uma rede fragmentada e distante da realidade vivida pelas mulheres (Dutra et al., 2013; Gomes, Erdmann, Mota, Carneiro, Andrade \& Koerich, 2013; Santi, Nakano \& Lettiere, 2010). Essa realidade evidencia que, mesmo que existam os serviços especializados, a atuação de um serviço, de forma isolada, não evita que a mulher passe por novas situações de violência (Meneghel, Bairros, Mueller, Monteiro, Oliveira \& Collaziol, 2011; Vieira et al., 2015).

Embora seja necessário estruturar melhor os serviços e preparar os profissionais para o acolhimento adequado das demandas das mulheres que sofrem violência, desde o início da década de 1980, podem-se destacar muitos avanços nas políticas públicas que ajudam a minimizar esse fenômeno. Delegacias especializadas de atendimento à mulher foram e estão sendo implantadas em vários municípios, além da criação de abrigos para mulheres em situação de violência, campanhas nacionais que discutem o tema e programas da saúde e da assistência social que buscam dar suporte a esse público (Oliveira \& Cavalcanti, 2007). Há ainda a Lei Maria da Penha (Lei $n^{o}$ 11.340/2006), juizados especializados de violência doméstica, organizações governamentais e não governamentais, inclusive serviços dirigidos aos agressores, particularmente aos agressores do sexo masculino (Lawson \& Brossart, 2009; Roy, Châteauvert \& Richard, 2013).

Estudos mostram que os serviços de saúde (Grossi et al., 2008; Schraiber \& D’Oliveira, 2008; Vieira et al., 2015), a polícia, delegacias/tribunais e líderes religiosos estão entre os recursos sociais e institucionais mais procurados pelas mulheres (Schraiber, Barros \& Castilho, 2010; Silva, Araújo, Valongueiro \& Ludermir, 2012). Santi, Nakano, e Lettiere (2010) verificaram que a abordagem realizada nos serviços que atendem vítimas de violência requer conhecimento dos serviços existentes nas diferentes áreas de atuação jurídica, policial, social, psicológica e de todas as outras possíveis redes de apoio informais, para que a mulher possa ter uma continuidade no atendimento oferecido a ela. 
Mesmo sabendo que ainda é preciso investimento para fortalecer o trabalho voltado para a temática da violência, a articulação entre os serviços que atuam nesse campo vem se solidificando em todo o País e os serviços começaram a ser mais conhecidos e mais acessados por esse público. É com o propósito de investigar se um desses serviços era reconhecido como parte da rede de apoio social e afetiva de mulheres vítimas de violência física e, ou, psicológica por parte de seus companheiros, que este estudo buscou, com os pressupostos da teoria bioecológica do desenvolvimento, identificar a percepção da equipe técnica e das usuárias sobre o acompanhamento realizado pelo Centro de Referência Especializado da Assistência Social (CREAS) - Proteção e Atendimento Especializado a Famílias e Indivíduos (PAEFI) de um município do Estado do Espírito Santo. A investigação foi parte de um trabalho de mestrado.

Urie Bronfenbrenner, na teoria Bioecológica do Desenvolvimento Humano, propõe que, para estudar o desenvolvimento, deve-se considerar a inter-relação entre quatro componentes: processo, pessoa, contexto e tempo. Os processos proximais são considerados o principal mecanismo do desenvolvimento humano e ocorrem por meio de formas de interação duradouras, regulares recíprocas e cada vez mais complexas entre um indivíduo ativo e outras pessoas, objetos e, ou, símbolos de seu ambiente imediato (Bronfenbrenner \& Morris, 2006). Os processos proximais variam em razão de outros fatores que devem ser observados: as características da pessoa, que são tanto produto como produtoras de desenvolvimento (temperamento, recursos adquiridos na interação com o ambiente, gênero etc.); os contextos nos quais a pessoa se relaciona, que são divididos em quatro sistemas: o "microssistema", contexto no qual o indivíduo estabelece relações face a face e no qual os processos proximais acontecem (família, amigos e instituições), o "mesossistema", que compreende a inter-relação entre os microssistemas dos quais a pessoa faz parte; o "exossistema", contexto que tem influência indireta no desenvolvimento da pessoa; e o "macrossistema", que compreende a cultura, os valores e as leis. Por fim, os processos proximais também variam em função do aspecto tempo, tanto o pessoal como o histórico (Bronfenbrenner \& Morris, 2006).

Considera-se que podem ser observados dois tipos de resultados desenvolvimentais que são relevantes neste estudo: os de competência e os de disfunção. Os resultados de competência estão relacionados a desfechos desenvolvimentais positivos e que normalmente ocorrem em ambientes que se apresentam favoráveis ao desenvolvimento. Os resultados de disfunção, por sua vez, estão relacionados à dificuldade em manter o controle e a integração do comportamento, e são mais prováveis de acontecer em contextos desfavoráveis ao desenvolvimento (Bronfenbrenner \& Morris, 2006), como em contextos 
no qual a violência ocorre (Carvalho-Barreto, Bucher-Maluschke, Almeida \& DeSouza, 2009). Nesses contextos, os processos proximais atuam, amortecendo os efeitos da desvantagem e de ambientes perturbadores (Bronfenbrenner \& Morris, 2006).

Assim como ocorre com outros temas estudados na perspectiva da Teoria Bioecológica (Rosa \& Tudge, 2017), ao pesquisar o que tem sido discutido nos artigos que problematizam a violência com essa teoria, verifica-se que aparecem mais frequentemente trabalhos que têm como foco o desenvolvimento de crianças e adolescentes. No entanto é possível constatar também que pesquisadores têm buscado, por meio desse referencial teórico, compreender e sugerir resoluções diante das diferentes demandas apresentadas por instituiçôes, famílias e profissionais que lidam com a questão da violência contra a mulher (Batista, Trigueiro, Lenardt, Mazza \& Labronici, 2013; Chronister, Harley, Aranda, Barr \& Luginbuhl, 2012; Antoni \& Koller, 2010, 2011).

Sobre as contribuições que têm sido avaliadas a partir do uso dessa teoria para o estudo do tema, Carvalho-Barreto et al. (2009) demonstram que o fato de a teoria abordar múltiplas dimensões, possibilita uma análise de vários fatores que compóem a problemática da violência. Os auto-res analisam a questão da violência contra a mulher, considerando as interações da díade conjugal, os vários contextos nos quais a mulher está inserida que podem compor sua rede de apoio, além do tempo, que pode explicitar histórias de violência ao longo das gerações.

Batista et al. (2013) avaliaram que a Teoria Bioecológica pode auxiliar os profissionais de Enfermagem a conhecer, de forma mais ampla, as necessidades da pessoa situada no contexto da violência e sua realidade, instrumentalizando-se para um cuidado mais qualificado. "Esse cuidado está ligado ao fato de a Teoria Bioecológica estar associada às experiências de vida da pessoa, que influencia e é influenciada, de maneira contextualizada, interativa e processual pelas suas interaçoos ambientais" (Batista et al., 2013, p. 174).

Assim, pode-se considerar que a Teoria Bioecológica do Desenvolvimento Humano pode fornecer elementos para um entendimento abrangente do tema, contribuindo, entre outras coisas, para a compreensão das relações que se estabelecem em um microssistema que fornece um serviço de atendimento a mulheres vítimas de violência, e como este promove interaçóes que podem favorecer o desenvolvimento saudável das mulheres usuárias do serviço. Acrescenta-se que uma das propostas da teoria é fundamentar cientificamente o planejamento de políticas e programas públicos que possam minimizar efeitos de ambientes perturbadores ao desenvolvimento (Brofenbrenner, 2001; Bronfenbrenner \& Morris, 2006). 


\section{MÉTODO}

\subsection{Participantes}

Esta pesquisa foi realizada no CREAS/PAEFI de um município do Estado do Espírito Santo. De acordo com o Mapa da Violência de 2012 (Waiselfisz, 2012), dentre os municípios brasileiros com taxas acima de 8 homicídios em 100 mil mulheres listados no documento, o referido Município ocupa a posição 84 a nível nacional, com uma taxa de 8,7 homicídios em 100 mil mulheres. Essa taxa representa praticamente o dobro da média nacional (Waiselfisz, 2012).

De acordo com a Resolução no 109, (2009), que aprovou a tipificação nacional de serviços socioassistenciais, o PAEFI é descrito como um serviço de apoio, orientação e acompanhamento a famílias com um ou mais de seus membros em situação de ameaça ou violação de direitos. No Município estudado, o serviço tinha, no momento da pesquisa, duas coordenações diferentes, as quais atendiam, respectivamente, adultos e crianças, e, ou, adolescentes. $\mathrm{O}$ estudo foi realizado com a equipe que atendia adultos. A equipe completa do serviço, no momento da pesquisa, era formada por 3 assistentes sociais, 2 psicólogos, 1 coordenador, 1 assessor jurídico e 1 educador social. Todos os integrantes da equipe foram convidados a participar da pesquisa. Não participaram das entrevistas 2 profissionais: a psicóloga, que era também a pesquisadora desta investigação, e o educador social, que estava de férias.

Entre as seis profissionais que foram entrevistadas, todas eram do sexo feminino, tinham média de idade de 31,16 anos, variando entre 25 e 38 anos. Três eram solteiras e 3 casadas. A maioria era católica, e todas se consideraram praticantes. Quatro se declararam pardas, uma como sendo preta e outra branca. Todas tinham ensino superior completo. O tempo de serviço no CREAS variou de 4 meses a 4 anos e meio.

Participaram da pesquisa dez mulheres usuárias do CREAS/PAEFI, que sofreram ou sofriam violência física e, ou, psicológica pelo companheiro e tinham pelo menos um filho. $\mathrm{O}$ convite foi feito a partir de indicação da equipe ou seleção da pesquisadora ao ter conhecimento do caso. As participantes tinham idades entre 34 a 45 anos, sendo a média de idade de 37,4 anos. Entre as participantes, 5 eram casadas, 4 eram divorciadas e 1 era viúva. Sete eram evangélicas e 3 católicas. A maioria frequentou o ensino médio (7), tendo três delas completado. Sete tinham mais de um filho (2 a 3), e 3, apenas um filho. Cinco usuárias trabalhavam de maneira informal e 4 formalmente, sendo que uma delas estava afastada do trabalho por problemas de saúde. Apenas uma não exercia trabalho remunerado. Em relação à renda, três participantes recebiam 
de um a dois salários mínimos, três recebiam de dois a quatro salários mínimos, duas ganhavam menos de um salário mínimo, uma não tinha renda, e uma não soube informar. Cinco mulheres sofreram violência psicológica, e as outras 5 sofreram também violência física pelos companheiros. Três participantes moravam com o companheiro e os filhos, 2 apenas com o filho, 2 residiam com os filhos e familiares, 1 com o companheiro, outra com a irmã e 1 morava sozinha. Sobre o tempo no serviço de atendimento, 4 mulheres tinham de um a cinco anos de acompanhamento, e 6 participantes tinham de quatro a dez meses de acompanhamento.

Tabela 1. Caracterização das usuárias participantes da pesquisa

\begin{tabular}{|c|c|c|c|c|c|c|c|c|c|c|c|}
\hline Participante & Idade & Estado civil & Escolaridade & Trabalho & Etnia & $\begin{array}{l}\text { Renda } \\
\text { (salários } \\
\text { mínimos) }\end{array}$ & Religião & Filhos & $\begin{array}{c}\text { Com quem } \\
\text { mora }\end{array}$ & $\begin{array}{l}\text { Violência } \\
\text { sofrida }\end{array}$ & $\begin{array}{l}\text { Tempo no } \\
\text { serviço }\end{array}$ \\
\hline Pâmela & 34 & Divorciada & $\begin{array}{l}\text { Ensino médio } \\
\text { incompleto }\end{array}$ & Informal & Parda & 1 & Católica & 1 filho & Irmã & Psicológica & Um ano \\
\hline Priscila & 34 & Casada & $\begin{array}{l}\text { Ensino médio } \\
\text { incompleto }\end{array}$ & Informal & Branca & Menos de 1 & Católica & 3 filhos & $\begin{array}{l}\text { Marido, } \\
\text { filhos }\end{array}$ & $\begin{array}{c}\text { Física e } \\
\text { psicológica }\end{array}$ & Dez meses \\
\hline Paula & 36 & Casada & $\begin{array}{l}\text { Ensino médio } \\
\text { incompleto }\end{array}$ & Do lar & Parda & Não tem & Evangélica & 2 filhos & $\begin{array}{l}\text { Mãe, } \\
\text { irmão, } \\
\text { filhos. }\end{array}$ & $\begin{array}{c}\text { Física e } \\
\text { psicológica }\end{array}$ & Dez meses \\
\hline Patrícia & 35 & Casada & $\begin{array}{l}\text { Ensino médio } \\
\text { incompleto }\end{array}$ & Informal & Parda & Menos de 1 & Evangélica & 2 filhos & $\begin{array}{l}\text { Marido, } \\
\text { filhos }\end{array}$ & Psicológica & Dois anos \\
\hline Poliana & 37 & Divorciada & $\begin{array}{l}\text { Ensino médio } \\
\text { completo }\end{array}$ & Informal & Branca & Não sabe & Evangélica & 3 filhos & Filho & Psicológica & Dez meses \\
\hline Paola & 40 & Divorciada & $\begin{array}{l}\text { Ensino médio } \\
\text { incompleto }\end{array}$ & $\begin{array}{c}\text { Empregada } \\
\text { (carteira } \\
\text { assinada) }\end{array}$ & Negra & $\begin{array}{c}2 \text { a } 3 \text { (mais } \\
\text { auxílio } \\
\text { reclusão) }\end{array}$ & Evangélica & 1 filho & Sozinha & $\begin{array}{c}\text { Física e } \\
\text { psicológica }\end{array}$ & Cinco anos \\
\hline Penélope & 38 & Divorciada & $\begin{array}{l}\text { Ensino } \\
\text { fundamental } \\
\text { incompleto }\end{array}$ & $\begin{array}{c}\text { Empregada } \\
\text { (afastada pelo } \\
\text { INSS) }\end{array}$ & Branca & 2 a 3 & Evangélica & 2 filhos & Filhos & Psicológica & $\begin{array}{l}\text { Nove } \\
\text { meses }\end{array}$ \\
\hline Paloma & 40 & Casada & $\begin{array}{l}\text { Ensino } \\
\text { superior } \\
\text { completo }\end{array}$ & $\begin{array}{c}\text { Empregada } \\
\text { (carteira } \\
\text { assinada) }\end{array}$ & Branca & 3 a 4 & Evangélica & 2 filhos & $\begin{array}{l}\text { Marido, } \\
\text { filhos }\end{array}$ & Psicológica & $\begin{array}{l}\text { Cinco } \\
\text { meses }\end{array}$ \\
\hline Paulina & 45 & Viúva & $\begin{array}{l}\text { Ensino médio } \\
\text { completo }\end{array}$ & Informal & Branca & 1. & Evangélica & 1 filho & $\begin{array}{c}\text { Companhei } \\
\text { ro }\end{array}$ & $\begin{array}{c}\text { Física e } \\
\text { psicológica. }\end{array}$ & Um ano \\
\hline Perla & 35 & Casada & $\begin{array}{l}\text { Ensino médio } \\
\text { completo }\end{array}$ & $\begin{array}{l}\text { Empregada } \\
\text { (concursada) }\end{array}$ & Parda & 1 a 2 & Católica & 2 filhos & $\begin{array}{l}\text { Mãe, } \\
\text { irmãos, } \\
\text { sobrinha, } \\
\text { filhos. }\end{array}$ & $\begin{array}{c}\text { Física e } \\
\text { psicológica. }\end{array}$ & $\begin{array}{l}\text { Quatro } \\
\text { meses }\end{array}$ \\
\hline
\end{tabular}

Fonte: elaborado pelas autoras. 
Tabela 2. Caracterização dos profissionais participantes da pesquisa

\begin{tabular}{|c|c|c|c|c|c|c|c|}
\hline Participante & Sexo & Idade & Etnia & Religião & $\begin{array}{l}\text { Estado } \\
\text { Civil }\end{array}$ & Escolaridade & $\begin{array}{c}\text { Tempo } \\
\text { de } \\
\text { serviço } \\
\text { no CREAS }\end{array}$ \\
\hline P1 & $\mathrm{F}$ & 33 & Negra & $\begin{array}{l}\text { Evangélica } \\
\text { praticante }\end{array}$ & Solteira & $\begin{array}{l}\text { Ensino superior } \\
\text { completo }\end{array}$ & 4 meses \\
\hline P2 & $\mathrm{F}$ & 25 & Parda & $\begin{array}{l}\text { Ca tólica } \\
\text { praticante }\end{array}$ & Solteira & $\begin{array}{l}\text { Ensino superior } \\
\text { completo }\end{array}$ & 4 meses \\
\hline P3 & $\mathrm{F}$ & 38 & Parda & $\begin{array}{l}\text { Ca tólica } \\
\text { praticante }\end{array}$ & Casada & $\begin{array}{l}\text { Ensino superior } \\
\text { completo }\end{array}$ & 6 meses \\
\hline P4 & $\mathrm{F}$ & 32 & Parda & $\begin{array}{l}\text { Católica } \\
\text { praticante }\end{array}$ & Casada & $\begin{array}{l}\text { Ensino superior } \\
\text { completo }\end{array}$ & $\begin{array}{l}4 \text { anos e } 6 \\
\text { meses }\end{array}$ \\
\hline P5 & $\mathrm{F}$ & 27 & Branca & $\begin{array}{l}\text { Evangélica } \\
\text { praticante }\end{array}$ & Casada & $\begin{array}{l}\text { Ensino superior } \\
\text { completo }\end{array}$ & $\begin{array}{l}4 \text { anos e } 6 \\
\text { meses }\end{array}$ \\
\hline P6 & $\mathrm{F}$ & 31 & Parda & $\begin{array}{l}\text { Ca tólica } \\
\text { praticante }\end{array}$ & Solteira & $\begin{array}{l}\text { Ensino superior } \\
\text { completo }\end{array}$ & $\begin{array}{l}1 \text { ano e } 3 \\
\text { meses }\end{array}$ \\
\hline
\end{tabular}

Fonte: elaborado pelas autoras.

\subsection{Procedimentos: coleta e análise dos dados}

Os dados foram coletados com um roteiro de entrevista que continha questôes sobre informações pessoais, demográficas e questões que buscavam conhecer o funcionamento do CREAS, além de opiniões e percepções sobre o serviço. As entrevistas com as usuárias e profissionais foram realizadas individualmente, em uma sala do CREAS, e tiveram duração média, respectivamente, de 50,8 minutos e de 24 minutos.

As entrevistas foram transcritas na íntegra, e os dados foram submetidos à análise de conteúdo proposta por Bardin (2002). Foi realizada uma primeira leitura de todo o material produzido pelas participantes, com posterior simplificação dos dados brutos e identificação de unidades de significado. Por fim, os resultados foram reorganizados nas categorias temáticas: "O CREAS PAEFI como microssistema para mulheres vítimas de violência"; "Articulação do CREAS com a rede de atendimento"; "O que pode ser melhorado no atendimento prestado pelo CREAS"; "O impacto do serviço na vida das usuárias e outras fontes de apoio". Os resultados foram analisados com base na teoria bioecológica do desenvolvimento humano. Para preservar o anonimato das participantes, foram utilizados nomes fictícios para as usuárias, e os profissionais foram identificados por meio da codificação de P1 a P6. A pesquisa foi realizada em consonância com os padrões éticos previstos na Resolução no 10/2012 do 
Conselho Federal de Psicologia e na Resolução no 466/(2012) do Conselho Nacional de Saúde, tendo sido avaliada pelo Comitê de Ética em Pesquisa com Seres Humanos (CEPSH) da Universidade Federal do....

\section{RESULTADOS}

\subsection{O CREAS PAEFI como microssistema para mulheres vítimas de violência}

Entre os serviços que eram ofertados pelo PAEFI, todas as profissionais participantes mencionaram: atendimento psicossocial, atendimento jurídico, acompanhamentos de casos junto à rede de serviços do Município, visitas domiciliares, visitas para averiguação de denúncias, grupo de mulheres.

A relação técnico-usuário foi apontada pela equipe como um dos pontos mais atraentes do serviço. Expressões como "confiabilidade", "entrosamento", "atendimento humanizado", "respeito ao que o usuário diz e deseja" foram citadas para se referir a essa relação. De acordo com os profissionais, quando a pessoa chega até o serviço, é recebida de forma imediata e acolhedora, existe uma escuta, além de os usuários serem informados sobre o sigilo das informações.

A avaliação positiva do acolhimento no serviço foi reiterada também pelas usuárias. A maioria delas não conhecia o serviço anteriormente. Os encaminhamentos até o CREAS ocorreram por indicação de pessoas conhecidas, como o pastor da igreja e pessoas próximas, ou por meio de outros serviços, como Conselho Tutelar, Centro de Referência da Assistência Social (CRAS), psicólogo da Secretaria de Saúde e policiais/delegacia. Apenas uma usuária já conhecia os serviços da rede socioassistencial do Município. Todas as usuárias participantes disseram que, ao chegar, estavam abaladas, sentindo-se sozinhas, com medo e assustadas: "Eu cheguei com um medo tão grande que eu achei que a solução estava pronta aqui e aí foi um processo. Cheguei, fui sendo atendida pelos profissionais, fui orientada e as coisas foram caminhando" (Paola).

O acolhimento, que é o primeiro atendimento recebido no serviço, foi caracterizado como "suporte", "apoio", "confiança", "atendimento rápido", "atenção especial", "cuidado", "carinho", "força", "desabafo". Nenhuma das participantes se queixou do atendimento recebido, além de frisarem que foram surpreendidas positivamente: "Achei que eu ia encontrar uma recepcionista que ia me encaminhar pra uma pessoa, marcar um horário, é o que a gente tá acostumado né?! Eu não imaginei que eu fosse ser atendida na hora. Então assim eu achei um cuidado muito especial" (Penélope). 
Todas as usuárias disseram que se sentiam "mais protegidas" inseridas no serviço. Frisaram que se sentiam compreendidas pelos profissionais e também pelos outros usuários, que tinham liberdade para desabafar e não se sentiam julgadas. Três participantes se emocionaram quando questionadas sobre como se sentiam inseridas no CREAS, pontuando que o serviço era "como se fosse a segunda família": "Eu era uma pessoa difícil de fazer amizades, então eu precisava desabafar, conversar com alguém, e eu sabia que aqui seria o local ideal, porque daqui não saía, os meus problemas iriam ficar aqui[... ]" (Paloma).

O grupo de mulheres foi pontuado como uma das atividades realizadas pelo CREAS. Com o objetivo de fortalecer as mulheres diante da situação de violência vivenciada, o grupo era realizado por uma psicóloga e uma assistente social. Era realizado semanalmente nas dependências do CREAS, no período diurno, com duração de aproximadamente uma hora e meia, e abrangia questóes de interesse das usuárias, como relação mãe e filho, casamento, autoestima e superação.

Mesmo sendo pontuado como uma atividade importante por todas as participantes do estudo, apenas 4 das 10 mulheres entrevistadas já haviam efetivamente participado do grupo. A maioria não pôde comparecer devido ao horário de trabalho, contudo eram acompanhadas por outras formas de atendimento existentes no local.

O grupo de mulheres foi descrito por profissionais e pelas quatro usuárias que participaram como sendo um espaço onde as pessoas podiam trocar experiências, fazer novas amizades, reconhecer e entender a dor do outro e a sua própria. As mulheres disseram que a experiência era "boa", "enriquecedora", que proporcionava "contato com pessoas diferentes", "troca de experiências", "apoio". A interação no grupo favorecia o desenvolvimento de novas habilidades e, ao compartilharem suas experiências, as mulheres adquiriam outras referências para analisar sua própria história. Verificou-se o estabelecimento de relações afetivas entre as participantes e que o afeto também era direcionado aos técnicos que conduziam a atividade: "Aqui eu sei que vou encontrar tudo o que eu preciso. Aqui eu fiz muitos amigos. Vejo pelo que as outras pessoas passam aí. Eu vejo que não é só eu que sofro" (Paula).

\subsection{Articulação do CREAS com a rede de atendimento}

Foi possível observar também o empenho dos profissionais pela busca de informações junto a outros órgãos/serviços, com o intuito de direcionar os usuários, proporcionando a articulação do PAEFI com a rede de serviços do Município. Todas as profissionais relataram que a articulação entre os serviços do Município, especialmente os da assistência e os da saúde, melhorou 
significativamente com o passar do tempo, porém frisaram que os contatos com os serviços de saúde eram os mais complicados. O contato com os órgãos do judiciário, salvo algumas exceções, foi descrito como frequente e satisfatório.

Além dos serviços ofertados dentro do CREAS, as mulheres foram encaminhadas para atendimento em outros órgãos e, ou, serviços do Município, de acordo com a demanda que cada uma delas trouxe. Entre os encaminhamentos realizados, podem-se citar: atendimento jurídico externo ao CREAS, Casa Abrigo para mulheres vítimas de violência doméstica, atendimento psicológico, atendimento ginecológico, Delegacia, Promotoria e encaminhamento para o Centro de Atenção Psicossocial- Alcool e Drogas (CAPS-AD), para tratamento de álcool e outras drogas para o companheiro. As usuárias demonstraram satisfação em relação aos atendimentos e enfatizaram a agilidade com que os atendimentos foram agendados e realizados. Alguns dos filhos das participantes também foram direcionados para serem atendidos: "Foi tudo bem rápido. Ela ligou para a menina e marcou na outra semana o atendimento ginecológico. Se não fosse por aqui, ia demorar com certeza" (Paula).

\subsection{O que pode ser melhorado no atendimento prestado pelo CREAS}

Sobre o que poderiam ser melhorados no serviço PAEFI, foi citada a necessidade de um defensor público dentro do serviço, já que o assessor jurídico dentro do CREAS apenas orienta o usuário, não atuando como advogado. Duas usuárias gostariam que houvesse mais presença da equipe técnica em sua residência. Outra disse que gostaria de maior suporte psicológico e, principalmente, atendimentos nos quais ela e os filhos estivessem juntos com os profissionais. Também foi citada a importância de oficinas que facilitassem o contato entre os próprios usuários e com os profissionais. Três mulheres não indicaram nada a ser melhorado, e uma usuária disse que faltava divulgação, pois a maioria não sabia da existência do lugar. Os profissionais apontaram necessidade de melhorias em relação ao espaço físico, ao aumento do quadro de funcionários, ao transporte, aos computadores e a não realização das averiguações de denúncias por elas (Disque 100), pois tirava o tempo de outros atendimentos.

\subsection{O impacto do serviço na vida das usuárias e outras fontes de apoio}

As dez usuárias entrevistadas pontuaram o CREAS/PAEFI como um importante apoio que as auxiliaram no processo de mudança. Três dentre essas 10 mulheres indicaram o CREAS como a única fonte de apoio.

Sete mulheres citaram, além do CREAS, outras fontes de apoio. Duas mulheres mencionaram Deus: "Se você se entrega de verdade e passa a ter uma 
intimidade com Deus, todas as coisas da sua vida vão mudar, não tem o que falar, é Deus" (Poliana). Outras duas usuárias relataram que receberam apoio de amigos próximos, além disso, quatro mulheres se consideravam "protagonistas" de toda mudança e história vivida e reconheciam o papel delas em todo o processo de reconstrução de suas vidas. Uma das mulheres disse que a escola do filho foi fundamental para que ela se reerguesse, e outra apontou um conjunto de fatores que a auxiliou a reconstruir sua vida:

$\mathrm{O}$ que ocasionou todas essas mudanças foi um conjunto de fatos. O sofrimento, o acompanhamento e o esclarecimento dos profissionais, todo o processo impulsionou essa mudança e eu mesma, eu vejo eu mesma como protagonista da situação (risos), né, e eu acredito que foi isso daí ne?! (Paloma).

Os técnicos acompanhavam as mudanças ocorridas na vida das usuárias a partir do momento em que elas eram acompanhadas pelo serviço. As profissionais acreditavam que, ao se disponibilizarem a frequentar aquele espaço e serem acompanhada, ao se "deixarem cuidar", já era evidenciada uma modificação na vida da usuária. Destacaram que, muitas vezes, a pessoa não acreditava, em um primeiro momento, que superaria a situação de violência, mas depois se surpreendia positivamente com o resultado.

Durante o acompanhamento realizado e a partir dos processos que foram estabelecidos, as mulheres perceberam mudanças em suas características pessoais. Apenas uma das mulheres relatou que estava tentando mudar alguns comportamentos, mas que ainda não havia conseguido se reestabelecer. Essa usuária havia sofrido violência física e psicológica pelo companheiro, e ficou durante um mês hospitalizada devido à agressão sofrida:

Eu tento mudar pelo pouco apoio que eu tenho, porque senão eu já tinha cometido alguma coisa pior. Eu não estou mais responsável como eu era, perdi aquele amor de cuidar de mim, da minha casa. [. . .]. Se tiver que comer, quem quer comer vai pra beira do fogão e faz, pra mim tanto faz (choro) (Priscila).

As outras participantes relataram mudanças. Pâmela e Penélope se consideraram mais sociáveis depois na inserção no CREAS e conseguiram observar mudança no afeto direcionado às pessoas mais próximas: "Hoje eu sou extremamente carinhosa com a minha mãe, com meu padrasto. Hoje eu procuro corrigir meus erros, pedir desculpa e sou até capaz de abraçar porque antes eu não abraçava, antes eu não sorria" (Pâmela).

Foram relatadas ainda mudanças relacionadas à saúde e à autoestima: "Eu tava tomando de três a quatro remédios pra dormir. Agora eu durmo sem problema nenhum" (Pâmela). "Antes eu me achava feia demais da conta. Agora eu me vejo uma mulher mais bonita e melhor" (Perla). 
Perla e Poliana tinham passado por um quadro depressivo e tentado suicídio, porém demonstraram estar mais estabilizadas emocionalmente. Paula, Patrícia, Paloma e Paola pontuaram estarem mais tranquilas, mais felizes e com maior foco para investir em si mesmas. Penélope e Perla disseram que aprenderam a ser menos desesperadas e mais ativas nas tomadas de decisóes, chegando a se surpreenderem com suas atitudes. Paola se sentia uma mulher mais informada, pois tinha maior conhecimento de seus direitos, e Paloma disse que se fortaleceu mais em seu matrimônio e em outras relações:

Acho que foi um momento traumático, que parecia que o mundo tinha acabado, só quem passa pra sentir. Mas eu mudei, amadureci, assim com certeza eu me fortaleci tanto no matrimônio como na maternidade e até mesmo no trabalho (Paloma).

\section{DISCUSSÃO}

Três aspectos pontuados pela teoria bioecológica foram analisados com base nas entrevistas das participantes: processo, contexto e pessoa. Pode-se dizer que, ao propiciar o engajamento em atividades e interaçôes interpessoais e o estabelecimento de interações face a face, com frequências regulares de participação, na qual as mulheres puderam tornar-se mais agentes de seu próprio desenvolvimento (Bronfenbrenner, 2001; Bronfenbrenner \& Morris, 2006), o CREAS/ PAEFI se configurou como sendo um microssistema para as usuárias participantes e as profissionais.

Em relação aos processos proximais, a relação profissional-usuário foi descrita positivamente por todos os participantes. A equipe destacou o atendimento imediato, que, de fato, é o que deve ser realizado em um serviço que faz parte da proteção social especial de acordo com a tipificação nacional de serviços socioassistenciais (Resolução no 109, 2009), pois, para procurarem o serviço, é preciso acionar recursos internos que, se não acolhidos prontamente pela equipe, poderiam fragilizar ainda mais a mulher e seu retorno, ao serviço ficar comprometido.

As usuárias do serviço pontuaram a receptividade e o acolhimento recebido no CREAS. Suas relações com os profissionais do local foram caracterizadas como sendo de respeito mútuo, confiabilidade, entrosamento e proteção. Juliano e Yunes (2014) enfatizam que a construção e consolidação da rede de apoio exige a convivência com reciprocidade, afetividade, respeito mútuo. As autoras também citam Bronfenbrenner como um autor que considera a importância da rede de apoio ao longo da vida, uma vez que a sua teoria tem como foco as interaçóes. Brito e Koller (1999) acrescentam sobre a importância da rede de apoio que, por meio dela, o indivíduo se sente acolhido, respeitado e valorizado, o que influencia diretamente o desenvolvimento da pessoa. 
Pode-se considerar que estiveram presentes características importantes para o estabelecimento dos processos proximais na relação profissional-usuário: a continuidade das interaçóes por um período, o afeto e a reciprocidade que possibilitaram que essas interações fossem significativas para as usuárias. Para Bronfenbrenner e Morris (2006), quanto mais afeto, reciprocidade e equilíbrio presentes nas relações, mais elas favorecem o desenvolvimento saudável. O envolvimento mútuo na relação é de extrema importância para que o serviço realmente possa trabalhar com a mulher que chega ao local, tentando direcioná-la para o estabelecimento de mudanças e reconstrução de sua vida. A reciprocidade gera um movimento que mobiliza o participante não somente a perseverar, mas também a se engajar em padrôes de interação cada vez mais complexos (Bronfenbrenner, 1996). Com o tempo e o acompanhamento, a mulher vai adquirindo maior conhecimento e autonomia para tomar as decisões necessárias para dar prosseguimento à sua vida, favorecendo, assim, seu desenvolvimento.

Pelo relato dos profissionais, quando a usuária se mostrava ativa e engajada nas atividades disponíveis, a equipe também ficava mais motivada. Destaca-se que, mesmo sendo a inserção de quem sofre violência assegurada por lei, o indivíduo não é obrigado a se vincular aos serviços. Guedes e Fonseca (2011) analisam que deve existir uma corresponsabilidade de profissionais e usuários, para que as mudanças realmente comecem a aparecer. Corrobora-se a afirmativa de Brito e Koller (1999) de que é a satisfação mútua dos integrantes e a demonstração de motivação, interesse, habilidade social e necessidade da relação que sustentam a rede de apoio.

Dessa forma, conhecer os aspectos subjetivos que mantêm o indivíduo engajado no serviço e o significado que as relações ali estabelecidas têm para ele é importante para que o trabalho seja bem-sucedido. Bronfenbrenner e Morris (2006) também destacam o valor de se analisar, nas investigaçóes, o aspecto fenomenológico da experiência, além de suas propriedades objetivas, como os sentimentos, as expectativas, dúvidas e esperança que as pessoas vivenciam.

Um dos trabalhos realizados no CREAS, citado pelos profissionais e usuárias do serviço, foi o grupo de mulheres. Pôde-se notar que o grupo promoveu, para aquelas que participaram, o estabelecimento de processos proximais, e ainda que sentimentos mutuamente positivos viabilizaram para as usuárias resultados desenvolvimentais de competência (Bronfenbrenner \& Morris, 2006), observados pelas mudanças descritas pelas participantes.

Estudos com outros enfoques legitimam o fato de que a experiência de trabalhos em grupo favorece o desenvolvimento de novas habilidades e estratégias para mulheres saírem da situação de violência (Meneghel, Barbiani, Steffen, 
Wunder, Roza, Rotermund \& Korndorfer, 2003; Moreira, 1999). Costa e Lopes (2012) também reconhecem a prática com grupos como potencializadora da promoção de saúde e do empoderamento individual e coletivo em relação às práticas violentas. Têm-se verificado que práticas que envolvem trabalhos com grupos dentro do CREAS estão sendo bem aceitas e surtindo efeitos positivos (Conselho Federal de Psicologia, 2009).

As mulheres descreveram que, no grupo, fizeram novas amizades, conseguiram apoio, conversaram sobre superação, aprenderam a respeitar as diferenças, além de criarem vínculos que se estenderam para outros contextos e situaçóes. As relações estabelecidas em grupos de convivência afetiva são capazes de tornar as pessoas mais eficazes diante de situações difíceis, pois os recursos pessoais e sociais adquiridos amenizam os efeitos negativos desse tipo de situação (Brito \& Koller, 1999).

Neste trabalho, verificou-se ainda a articulação entre os vários microssistemas que compõem o mesossistema das mulheres. Bronfenbrenner e Morris (2006) descrevem o mesossistema como a reunião de microssistemas e pontuam que, cada vez que o indivíduo passa a frequentar um novo ambiente, esse contexto é ampliado. Uma usuária relata a influência que a escola da filha teve em sua vida, para que ela chegasse até o CREAS em busca de ajuda. Outra participante explica que, ao frequentar a igreja e estabelecer relações significativas com as pessoas do local, foi mobilizada a procurar o serviço. Além disso, as mulheres, no geral, relataram a importância de amigos e vizinhos que estavam mais próximos, e que as acolheram quando elas precisaram. Estudos afirmam o valor dado aos amigos e pessoas mais próximas, já que estas pessoas são uma das primeiras a serem procuradas pela mulher que vivenciou a violência, quando ela decide procurar ajuda (Dutra et al., 2013; Silva et al., 2012).

Posteriormente à inserção no CREAS, observou-se que as participantes passaram a frequentar outros microssistemas e, assim, ampliaram a rede de relações interpessoais, formando novas relações entre elas e a família, o CREAS, entre outros. É possível verificar que o estabelecimento de processos proximais fortes estabelecidos em um microssistema tende a repercutir nos demais microssistemas nos quais as mulheres estão inseridas. Um exemplo disso é que as mulheres descrevem que a inserção no CREAS as auxiliaram na mudança de comportamento e tratamento em relação à família. O profissional, por sua vez, preocupava-se em fortalecer e ampliar a interação com as pessoas e locais que eram significativos para as usuárias e fortalecer a família como um todo, garantindo que a mulher e outros membros da família tivessem o acompanhamento de outros órgãos e serviços. 
Com relação aos encaminhamentos, foi verificada a articulação do CREAS com outros serviços da rede e uma maior dificuldade em relação aos serviços de saúde. Estudo realizado pelo Conselho Federal de Psicologia (2012) corrobora tais questionamentos, quando descreve que a pesquisa nacional feita pelo Crepop (Conselho Federal de Psicologia;Centro de Referência Técnica em Psicologia e Políticas Públicas, 2009) aponta a articulação com a rede de saúde como um dos maiores desafios quando comparada com outros serviços.

Após o acompanhamento no PAEFI, as mulheres perceberam mudanças em suas características pessoais. Aspectos como passividade, medo, desespero, problemas de saúde, que se caracterizam como efeitos de disfunção, foram descritos pelas mulheres como parte do que vivenciavam ao serem inseridas no serviço. Com o apoio do CREAS, verificou-se o desenvolvimento de características que revelam efeitos de competência e diminuição dos efeitos de disfunção. Algumas mulheres relataram ter adquirido maior conhecimento de seus direitos, conhecimento em relação aos tipos de violência elencadas na Lei Maria da Penha e também em relação aos serviços que poderiam acessar em situações de violência. Nota-se, portanto, o desenvolvimento do que Bronfenbrenner e Morris (2006) identificaram como características de recurso. Bronfenbrenner e Morris (1998) afirmam que a aprendizagem favorece o desenvolvimento de características de recursos, relativos à pessoa, a aquisição de habilidades, de competências e de conhecimentos para o efetivo funcionamento dos processos proximais em outros contextos, confirmando, assim, a importância de a mulher estar inserida em uma rede de apoio. Conforme Garmezy e Masten (1994), a rede de apoio contribui para o aumento da competência individual e, consequentemente, reforça a autoimagem e a autoeficácia necessárias para alcançar um objetivo. $\mathrm{O}$ conhecimento dos direitos adquiridos é de extrema importância, pois auxilia as mulheres vítimas de violência a argumentarem e solicitarem o que a Lei pode oferecer a elas nessa situação, além de diminuir a sua vitimização, pois elas passam a ter maior autonomia para acionar os órgãos e serviços que atendem a essa problemática. Bronfenbrenner e Ceci (1994) acrescentam que os processos proximais conduzem a resultados de desenvolvimento que possibilitam à pessoa, entre outras coisas, direcionar e controlar o próprio comportamento, enfrentar, de forma bem-sucedida, o stress, estabelecer e manter relaçóes recompensadoras para os envolvidos e construir e transformar o próprio ambiente psicológico, social e simbólico, competências importantes para o enfrentamento da violência.

Outras características que foram relatadas pelas usuárias, após a entrada no serviço, foram: desenvolvimento da expressão de afeto positivo, equilíbrio na saúde física, melhoria no sono, amadurecimento, independência, autonomia nas tomadas de decisões, autoestima e autoimagem fortalecidas, ou seja, características 
de força. Essas características cada participante desenvolveu sustentam o processo proximal (Bronfenbrenner \& Morris, 2006), destacando a inter-relação entre a mulher usuária do serviço e o profissional, e, posteriormente, com a família e as outras relações. As características destacadas pelas usuárias despertaram nos profissionais a ideia de que a mulher está engajada na atividade, fazendo com que este realmente invista no acompanhamento daquela mulher, que significa o CREAS como integrante de sua rede de apoio. Constata-se que a construção do vínculo no transcorrer do trabalho com mulheres vítimas de violência propicia aos profissionais o estabelecimento de confiança e abertura por parte delas, favorecendo o engajamento no atendimento e o fortalecimento das mulheres (Costa \& Lopes, 2012; Grossi et al., 2008).

\section{CONSIDERAÇÕES FINAIS}

Este estudo teve como objetivo principal investigar se e de que forma o CREAS/PAEFI de um município do Estado do Espírito Santo, integrava a rede de apoio social e afetiva de mulheres vítimas de violência pelo companheiro, analisando as interaçôes estabelecidas nesse contexto com a teoria bioecológica do desenvolvimento. Ao discutirem a rede de atendimento para mulheres vítimas de violência, estudos mostram que as mulheres, em geral, não encontram o que esperam e o que necessariamente precisam nesses serviços (Dutra et al., 2013; Santi, Nakano \& Lettiere, 2010; Santos \& Vieira, 2011). Porém os resultados deste estudo trazem uma realidade diferente. As mulheres pesquisadas relataram que receberam encaminhamentos adequados e que foram surpreendidas com o atendimento recebido, demonstrando encontrar mais do que realmente esperavam quando chegaram ao CREAS. Mesmo não conseguindo suprir todas as demandas colocadas por elas, as usuárias consideraram o suporte do serviço significativo e promotor de mudanças. A equipe pontuou dificuldades relacionadas à falta de estrutura do serviço, o que chama a atenção para a necessidade de mais investimentos para que os profissionais, tendo melhores condições de trabalho, consigam oferecer também um melhor acompanhamento à mulher e à família. No entanto, mesmo com algumas dificuldades, os profissionais demonstram conhecer a rede de atendimento a esse público e conseguir uma boa articulação com esta.

Com base nos pressupostos da teoria bioecológica, os resultados da pesquisa sinalizam o CREAS/PAEFI como um microssistema significativo na vida das mulheres vítimas de violência. Além disso, foi possível perceber trajetórias desenvolvimentais positivas, nas quais os processos proximais evidenciados pelos atendimentos realizados no serviço, pela reciprocidade e pelo afeto presentes nas 
relações entre as pessoas envolvidas, viabilizaram a percepção de mudanças na vida das mulheres.

Como limites deste estudo, pode-se apontar o fato de que o aspecto tempo não foi analisado com mais abrangência. Um caminho interessante seria o desenvolvimento de um estudo de caráter longitudinal, permitindo, assim, uma análise mais aprofundada das continuidades e mudanças percebidas na vida das usuárias de acordo com a sua participação no serviço e com os processos proximais ali desenvolvidos, além do enfoque a outros aspectos, como o impacto da violência na vida dos filhos, na construção da parentalidade e da conjugalidade. Contudo, considera-se que os dados levantados mostraram elementos importantes da realidade de um serviço, tanto na visão dos profissionais como na percepção das usuárias, e que a análise com a teoria bioecológica do desenvolvimento humano pode oferecer contribuições para análise das questôes discutidas neste trabalho. O que pode ser somado ao campo do conhecimento existente, contribuindo para a literatura sobre o tema e a fundamentação teórica na implementação de políticas públicas que, de fato, integrem as reais necessidades de mulheres em situação de violência. 


\section{REFERENCIAS}

Albuquerque Netto, L. de., Moura, M. A. V., Queiroz, A. B. A., Tyrrell, M. A. R. \& Bravo, M. del M. P. (2014). Violência contra a mulher e suas consequências. Acta Paulista de Enfermagem, 27(5), 458-464.

Antoni, C. de \& Koller, S. H. (2010). Uma família fisicamente violenta: uma visão pela teoria bioecológica do desenvolvimento humano. Temas em Psicologia, 18(1), 17-30.

Antoni, C. de \& Koller, S. H. (2011). A pesquisa ecológica sobre violência no microssistema familiar. In S. H. Koller (Org.), Ecologia do desenvolvimento humano: pesquisa e intervenção no Brasil (pp. 315-339). São Paulo: Casa do Psicólogo.

Bardin, L. (2002). Análise de conteúdo. L. A. Reto \& A. Pinheiro (Trads.). Lisboa: Edições 70.

Barros, É. N. de, Silva, M. A., Falbo Neto, G. H., Lucena, S. G., Ponzo, L. \& Pimentel, A. P. (2016). Prevalência e fatores associados à violência por parceiro íntimo em mulheres de uma comunidade em Recife/Pernambuco, Brasil. Ciência \& Saúde Coletiva, 21(2), 591-598.

Batista, J. M. da S., Trigueiro, T. H., Lenardt, M. H., Mazza, V. de A. \& Labronici, L. M. (2013). O modelo bioecológico: desvendando contribuições para a práxis da enfermagem diante da violência doméstica. Escola Anna Nery, $17(1), 173-178$.

Brito, R. C. \& Koller, S. H. (1999). Desenvolvimento humano e redes de apoio social e afetivo. In A. M. Carvalho (Org.), O mundo social da criança: natureza e cultura em ação. (pp. 115-126). São Paulo: Casa do Psicólogo.

Bronfenbrenner, U. (1996). A ecologia do desenvolvimento: experimentos naturais e planejados. Porto Alegre: Artmed.

Bronfenbrenner, U. (2001). The bioecological theory of human development. In N. J. Smelser \& P. B. Baltes (Eds.), International encyclopaedia of the social and behavioural sciences (Vol. 10, pp. 6963-6970). New York: Elsevier.

Bronfenbrenner, U. \& Ceci, S. J. (1994). Nature-nurture reconceptualized: a bioecological model. Psychological Rewiew, 101, 568-586. 
Bronfenbrenner, U. \& Morris, P. A. (1998). The ecology of developmental processes. In W. Damon \& R. M. Lerner (Orgs.), Handbook of child psychology: theoretical models of human development. (Vol. 1, pp. 993-1028). New York: John Wiley.

Bronfenbrenner, U. \& Morris, P. A. (2006). The bioecological model of human development. In W. Damon \& R. M. Lerner (Eds.), Handbook of child psychology: theoretical models of human development. (Vol. 1, pp. 793-828). New York: John Wiley \& Sons.

Carvalho-Barreto, A., Bucher-Maluschke, J. S. N. F., Almeida, P. C. \& DeSouza, E. (2009). Desenvolvimento humano e violência de gênero: uma integração bioecológica. Psicologia: Reflexão e Crítica, 22(1), 86-92. Recuperado a partir de https://dx.doi.org/10.1590/S0102-79722009000100012

Chronister, K. M., Harley, E., Aranda, C. L., Barr, L. \& Luginbuhl, P. (2012). Community-based career counseling for women survivors of intimate partner violence: a collaborative partnership. Journal of Career Development, 39(6), 515-539.

Conselho Federal de Psicologia. (2012). Referências técnicas para a prática de psicólogas (os) no Centro de Referência Especializado da Assistência Social-CREAS. Brasília: CFP. Recuperado a partir de http://crepop.pol.org.br/novo/wpcontent/ uploads/2013/03/CREPOP_CREAS_.pdf

Conselho Federal de Psicologia, Centro de Referência Técnica em Psicologia e Políticas Públicas (2009). Documento relatório preliminar de análise qualitativa dos dados de pesquisa sobre a atuação dos/as psicólogos/as no CREAS e outros serviços especiais de acolhida e atendimento domiciliar do SUAS. São Paulo: Instituto de Psicologia da Universidade de São Paulo.

Costa, M. C. \& Lopes, M. J. M. (2012). Elementos de integralidade nas práticas profissionais de saúde a mulheres rurais vítimas de violência. Revista da Escola de Enfermagem da USP, 46(5), 1088-1095.

Durand, J. G., Schraiber, L. B., França-Junior, I. \& Barros, C. (2011). Repercussão da exposição à violência por parceiro íntimo no comportamento dos filhos. Revista de Saúde Pública, 45(2), 355-364. Recuperado a partir de https://dx.doi.org/10.1590/S0034-89102011005000004

Dutra, M. L., Prates, P. L., Nakamura, E. \& Villela, W. V. (2013). A configuração da rede social de mulheres em situação de violência doméstica. Ciência \& Saúde Coletiva, 18(5), 1293-1304. 
Garcia L. P., Duarte, E. C., Freitas, L. R. S. \& Silva, G. D. M. (2016, abril). Violência doméstica e familiar contra a mulher: estudo de casos e controles com vítimas atendidas em serviços de urgência e emergência. Cadernos de Saúde Pública, 32(4), 1-11. Recuperado a partir de https://dx.doi.org/10.1590/0102$311 \mathrm{X} 00011415$

Garmezy, N. \& Masten, A. (1994). Chronic adversities. In M. Rutter, E. Taylor \& L. Herson (Eds.), Child and adolescent psychiatry. (pp. 191-207). Oxford: Blaackwell.

Gomes, N. P., Erdmann, A. L., Mota, L. L., Carneiro, J. B., Andrade, S. R.,\& Koerich, C. (2013). Encaminhamentos à mulher em situação de violência conjugal. O Mundo da Saúde, 37(4), 377-384.

Grossi, P. K., Tavares, F. A. \& Oliveira, S. B. (2008). A rede de proteção à mulher em situação de violência doméstica: avanços e desafios. Athenea Digital, 14, 267-280.

Guedes, R. N. \& Fonseca, R. M. G. S. (2011). A autonomia como necessidade estruturante para o enfrentamento da violência de gênero. Revista da Escola de Enfermagem da USP, 45(2), 1731-1735.

Juliano, M. C. C. \& Yunes, M. A. M. (2014). Reflexōes sobre rede de apoio social como mecanismo de proteção e promoção de resiliência. Ambiente \& Sociedade, 17(3), 135-154.

Koller, S. H. \& Antoni, C. de (2011). Violência Intrafamiliar: uma visão ecológica. In S. H. Koller (Org.), Ecologia do desenvolvimento humano: pesquisa e intervenção no Brasil. (pp. 297-314). São Paulo: Casa do Psicólogo.

Labronici, L. M. (2012). Processo de resiliência nas mulheres vítimas de violência doméstica: um olhar fenomenológico. Texto \& Contexto - Enfermagem, 21(3), 625-632.

Lawson, D. M. \& Brossart, D. F. (2009). Attachment, interpersonal problems, and treatment outcome in group therapy for intimate partner violence. Psychology of Men \& Masculinity, 10(4), 288-301.

Lei no 11.340, de 7 de agosto de 2006 (2006, 7 agosto). Dispóe sobre a Lei Maria da Penha. Diário Oficial da União, Brasília. Recuperado a partir de http://www.planalto.gov.br/ccivil_03/_ato2004-2006/2006/lei/111340.htm 
Meneghel, S. N., Bairros, F., Mueller, B., Monteiro, D., Oliveira, L. P. \& Collaziol, M. E. (2011). Rotas críticas de mulheres em situação de violência: depoimentos de mulheres e operadores em Porto Alegre, Rio Grande do Sul. Cadernos de Saúde Pública, 27(4), 743-752.

Meneghel, S. N., Barbiani, R., Steffen, H., Wunder, A. P., Roza, M. D., Rotermund, J. B. \& Korndorfer, C. (2003). Impacto de grupos de mulheres em situação de vulnerabilidade de gênero. Cadernos de Saúde Pública, 19(4), 955-963.

Moreira, M. A. (1999). Aprendizagem significativa. Brasília: Editora Universidade de Brasília.

Oliveira, A. P. G. \& Cavalcanti, V. R. S. (2007). Violência doméstica na perspectiva de gênero e políticas públicas. Journal of Human Growth and Development, 17(1), 39-51. Recuperado a partir de http://pepsic.bvsalud.org/ scielo.php?script=sci_abstract $\&$ pid $=$ S0104-12822007000100005

Peralta, R. L. \& Fleming, M. F. (2003). Screening for intimate partner violence in a primary care setting: the validity of "feeling safe at home" and prevalence results. The Journal of the American Board of Family Medicine, 16(6), 525-532.

Resolução no 109, de 11 de novembro de 2009 (2009, 25 novembro). Tipificação nacional de serviços socioassistenciais. Diário Oficial da União, Brasília.

Resolução no 466, de 12 de dezembro de 2012. (2012, 12 dezembro). Brasília: Ministério da Saúde, Conselho Nacional de Saúde. Recuperado a partir de http://bvsms.saude.gov.br/bvs/saudelegis/cns/2013/res0466_12_12_2012. html.

Rodgers, K. (1994). Wife assault: the findings of a national survey. Juristat Service Bulletin, 14, 1-22.

Rodrigues, V. P., Rodrigues, A. D., Lira, M. O. de S. C., Couto, T. M. \& Diniz, N. M. F. (2016). Relaçôes familiares no contexto da violência de gênero. Texto \& Contexto - Enfermagem, 25(3), 1-9.

Rosa, E. M. \& Tudge, J. (2017). Teoria bioecológica do desenvolvimento humano: considerações metodológicas. In A. C. G. Dias \& E. M. Rosa (Orgs.), Metodologias de pesquisa e intervenção com crianças, adolescentes e jovens. Vitória: Edufes. 
Roy, V., Châteauvert, J. \& Richard, M. C. (2013). An ecological examination of factors influencing men's engagement in intimate partner violence groups. Journal of Interpersonal Violence, 28(9), 1798-1816.

Saffioti, H. I. B. (1997). Equidade e paridade para obter igualdade. O Social em questão, 1(1), 63-70.

Samuelson, M., Thernlund, G. \& Ringstrom, J. (1996). Using the five field map to describe the social network of children: a metodological study. Internacional Journal of Behavioral Development, 19(2), 327-345.

Santi, L. N., Nakano, A. M. S. \& Lettiere, A. (2010). Percepção de mulheres em situação de violência sobre o suporte e apoio recebido em seu contexto social. Texto \& Contexto - Enfermagem, 19(3), 417-424.

Santos, A. C. W. \& Moré, C. L. O. O. (2011). Impacto da violência no sistema familiar de mulheres vítimas de agressão. Psicologia: Ciência e Profissão, 31(2), 220-235.

Santos, M. A. \& Vieira, E. M. (2011). Recursos sociais para apoio às mulheres em situação de violência em Ribeirão Preto, SP, na perspectiva de informantes chave. Interface - Comunicação, Saúde, Educação, 15(36), 93-108.

Schraiber, L. B., Barros, C. R. S. \& Castilho, E. A. (2010). Violência contra as mulheres por parceiros íntimos: usos de serviços de saúde. Revista Brasileira de Epidemiologia, 13(2), 237-245.

Schraiber, L. B. \& D’Oliveira, A. F. P. L. (2008). Romper com a violência contra a mulher: como lidar desde a perspectiva do campo da saúde. Athenea Digital, $14,229-236$.

Sherbourne, C. D. \& Stewart, A. L. (1991). The MOS social support survey. Social Science \& Medicine, 32(6), 705-714.

Silva, R. A., Araújo, T. V. B., Valongueiro, S. \& Ludermir, A. B. (2012). Enfrentamento da violência infligida pelo parceiro íntimo por mulheres em área urbana da região Nordeste do Brasil. Revista Saúde Pública, 46(6), 10141022.

Sluzki, C. E. (1997). A rede social na prática sistêmica: alternativas terapêuticas. São Paulo: Casa do Psicólogo. 
Snow, D. L. \& Swan, S. C. (2006). The development of a theory of women's use of violence in intimate relationships. Violence Against Women, 12(11), 10261045.

Vieira, L. B., Becker, L., Souza, I. E. O., Tocantins, F. R. \& Pina-Roche, F. (2015, setembro-outubro). Apoio à mulher que denuncia o vivido da violência a partir de sua rede social. Revista Latino-Americana de Enfermagem, 23(5), 865-873.

Villela, W. V. \& Lago, T. (2007). Conquistas e desafios no atendimento das mulheres que sofreram violência sexual. Cadernos de Saúde Pública, 23(2), 471-475.

Waiselfisz, J. J. (2012). Mapa da violência: os novos padröes da violência homicida no Brasil. São Paulo: Instituto Sangari. 